\title{
Event-related brain potentials dissociate repetition effects of high- and low-frequency words
}

\author{
MICHAEL D. RUGG \\ University of St. Andrews, St. Andrews, Fife, Scotland
}

\begin{abstract}
Event-related brain potentials (ERPs) were recorded while subjects detected nonwords interspersed among sequences of words of high or low frequency of occurrence. In Phase 1, a proportion of the words were repeated after six intervening items. In Phase 2, which followed after a break of approximately $15 \mathrm{~min}$, the words were either repeats of items presented in the previous phase or new. Unrepeated low-frequency words evoked larger N400 components than did highfrequency items. In Phase 1, this effect interacted with repetition, such that no frequency effects were observed on $\mathrm{N} 400 \mathrm{~s}$ evoked by repeated words. In addition, the post-500-msec latency region of the ERPs exhibited a substantial repetition effect for low-frequency words, but did not differentiate unrepeated and repeated high-frequency words. In Phase 2, ERPs evoked by "old" and "new" high-frequency words did not differ in any latency region, while those evoked by old and new low-frequency words differed only after $500 \mathrm{msec}$. The interactive effects of frequency and repetition suggest that these variables act jointly at multiple loci during the processing of a word. The specificity of the post-500-msec repetition effect for low-frequency words may reflect a process responsive to a discrepancy between words' intra and extraexperimental familiarity.
\end{abstract}

The frequency with which a word occurs in the language is a powerful determinant of the efficiency of its processing in a range of laboratory tasks. With some exceptions (e.g., Balota \& Chumbley, 1984; McCann \& Besner, 1987), accounts of the effects of word frequency have assumed that it largely reflects the relative ease with which words of differing frequencies access and/or activate their stored lexical representations (e.g., Forster, 1976; Gordon, 1983; McClelland \& Rumelhart, 1981; Monsell, Doyle, \& Haggard, 1989; Morton, 1969).

Another robust phenomenon, also observed in a range of tasks, is the word-repetition effect. This refers to the greater efficiency with which repeated as opposed to unrepeated words are processed. The repetition effect is remarkably durable; in both lexical decision (Scarborough, Cortese, \& Scarborough, 1977) and tachistoscopic identification tasks (Jacoby, 1983; Jacoby \& Dallas, 1981), it persists over intervals of $24 \mathrm{~h}$ or more.

In a number of studies, it has been reported that word frequency and repetition interact, such that low-frequency words benefit from repetition to a greater degree than high-frequency words do (e.g., Duchek \& Neely, 1989; Forster \& Davis, 1984; Jacoby \& Dallas, 1981; Norris, 1984; Scarborough et al., 1977; but see Humphreys, Besner, \& Quinlan, 1988, for a recent failure to observe this effect). A parsimonious way of accounting for the interaction between frequency and repetition is to assume

This work was supported by the Medical Research Council of the U.K and the Wellcome Trust. The helpful comments of J. I. Chumbley, M. Doyle, G. Humphreys, and three anonymous reviewers are gratefully acknowledged. Reprint requests should be sent to M. D. Rugg, Wellcome Brain Research Group, Department of Psychology, University of St. Andrews, St. Andrews, Fife KY16 9JU, United Kingdom. (cf. Monsell, 1985) that: (1) word frequency and repetition act at a common locus, so that the effect of exposing a word is temporarily to increment its "effective frequency" beyond that provided by prior encounters with the word outside the experimental context; and (2) the time course of the decay of this incrementing process is such that a single exposure increases the effective frequency of low-frequency words to a greater extent than it does that of high-frequency words. Within this general framework, the word-frequency effect is conceptualized as reflecting the "steady state" of what in actuality is a highly labile system, the dynamics of which are reflected by the word-repetition effect.

An alternative view of the interaction between word frequency and repetition stems from an interpretation of repetition effects in terms of the operation of episodic rather than lexical memory. In this view (see, e.g., Feustel, Shiffrin, \& Salasoo, 1983; Jacoby \& Dallas, 1981), the benefit accruing to a repeated word results not from the modification of a preexisting representation in lexical memory (e.g., as argued by Monsell, 1985), but from the existence of a context-specific memory of the word's first presentation. According to Jacoby and Dallas (1981; see also Jacoby, 1983), the interaction of repetition with frequency reflects the fact that high-frequency words are experienced more often, and in a wider range of contexts (some of which will presumably be similar to those found in most experiments), than low-frequency words are. High-frequency words therefore stand to benefit less from an additional single exposure.

As noted by Monsell (1985), the principal difference between episodic and lexical accounts of repetition and frequency effects centers on the question of whether prior processing episodes are represented in a context-sensitive 
fashion. Both accounts assume that a major locus of the interaction between repetition and frequency is to be found during identification, and that the two variables act jointly to yield the effective frequency of a word at the time of its exposure. McClelland and Rumelhart (1985) have attempted to reconcile the lexical and episodic positions, describing a parallel distributed model in which no explicit distinction is drawn between context-dependent and context-independent memories for prior processing episodes.

Using the lexical decision task, Forster and Davis (1984) attempted to separate lexical and episodic components of repetition and frequency by contrasting the nature of the priming caused by masked and unmasked words. The use of the masking manipulation was based on the assumption that primes that are not explicitly identified activate lexical memory, but are not encoded episodically (see Humphreys et al., 1988, for an alternative view). Masked primes were found to yield short-lasting repetition effects that were equal in magnitude for lowand high-frequency words, whereas unmasked primes produced repetition effects that were both long-lasting and frequency-sensitive. Forster and Davis therefore concluded that long-term word-repetition effects, and the interaction of these effects with frequency, depend exclusively on episodic factors.

Forster and Davis's (1984) data do not challenge the view that, under normal viewing conditions, word repetition and frequency combine to influence the ease of a word's identification. Even if the action (and interaction) of these variables is mediated entirely by episodic factors, this does not preclude the possibility that they influence an "early" stage of word processing such as lexical access, in addition to any influence they might exert on postlexical processes.

Word frequency is an important variable not only in word identification tasks, but also in tasks explicitly involving episodic memory. It has consistently been found that low-frequency words are recognized more accurately than high-frequency words (see, e.g., Glanzer \& Bowles, 1976; Gorman, 1961; Jacoby \& Dallas, 1981; Kinsbourne \& George, 1974; Mandler, Goodman, \& Wilkes-Gibbs, 1982; Rao \& Proctor, 1984). One class of approaches to explaining the recognition memory advantage of lowfrequency words, exemplified by Mandler (1980) and Jacoby and Dallas (1981), can be related to accounts of repetition and frequency effects on word identification. Although differing in detail in important respects, these approaches assume that recognition judgments are influenced not only by a consciously mediated memory search, but also by the same processes that underlie the word-repetition effect in identification tasks. It is assumed that the ease (or "fluency," in Jacoby's terminology) with which an item is identified in a particular context is an important determinant of its perceived familiarity (termed here the item's local familiarity). Local familiarity can be compared with the level of familiarity that would be expected on the basis of the frequency with which the stimulus has been encountered outside the experiment (baseline familiarity, predicted by frequency of occurrence in the language; Gernsbacher, 1984; Gordon, 1985). Local familiarity will be greater than baseline when an experimental item is repeated more frequently than typically occurs in everyday life. A discrepancy between local and baseline familiarity can therefore provide a cue as to whether an item has recently been encountered, and it can thereby act as a guide for recognition judgments. The recognition advantage for low-frequency words occurs because the fluency with which these words are identified changes with repetition more than the fluency of high-frequency items does, leading to a greater discrepancy between local and baseline familiarity.

Although two-process theories posit an explicit mechanism (perceptual fluency) for the derivation of local familiarity, it is less clear how an item's baseline familiarity is obtained. Presumably, the latter variable depends on the retrieval from long-term memory of information about the item's prior occurrences. The nature of this memory representation is not critical for two-process theories, as long as it can be assumed that the information is largely unaffected by local familiarity. Hintzman (1988) provides a review of competing approaches to the question of how frequency of occurrence might be encoded in and retrieved from memory.

Accounts of the interactive effects of frequency and repetition on word identification need only propose that these variables combine to determine the effective frequency of a word. However, as noted previously, twoprocess theories of recognition memory must go further, and assume that although short-term repetition influences a word's local familiarity (by changing its perceptual fluency), this does not significantly change the word's baseline familiarity. If this were not so, there would be no means of determining the difference between the two (cf. Jacoby and Dallas, 1981; Mandler et al., 1982). Indeed, according to these theories, even if repetition were to equate the local familiarity of low- and high-frequency words, the processing of the two classes of items would still be distinguishable, by virtue of processes sensitive to the degree of mismatch between local and baseline familiarity. A major aim of the present experiment is to search for direct evidence of an on-line process sensitive to a discrepancy between words' local and baseline familiarity. Such evidence would provide strong independent support for one of the major tenets of two-process theories of recognition memory.

The overriding majority of work done to investigate variables such as word repetition has involved behavioral measures. A complementary approach is to record the physiological changes evoked by stimuli in such experiments, and to use these changes to make inferences about the timing and nature of stimulus processing under different experimental conditions. One such physiological measure consists of event-related brain potentials (ERPs). The rationale for the use of ERPs in studies of language processing, the methodological requirements of such 
studies, and the major findings that have emerged have been described in detail previously (Hillyard \& Kutas, 1983; Kutas and Van Petten, 1988; Picton, 1981; Rugg, 1987; Rugg, Kok, Barrett, \& Fischler, 1986). Briefly, ERP waveforms are obtained by averaging epochs of scalp EEG that have been sampled in a time-locked fashion with respect to the onset of an event such as the exposure of a word. The averaging process attenuates electrical activity of the brain that is random with respect to the evoking event, while retaining the activity that is consistently associated with the event. ${ }^{1}$ An ERP waveform thus provides a real-time record of the neural activity, detectable at the scalp, that is associated with the processing of a set of stimuli. The deflections, or peaks, in an ERP waveform are conventionally labeled by their polarity and approximate latency or ordinal position. These features are often referred to as components, and usually have a characteristic amplitude distribution over the scalp. Scalp distribution can be an important means of distinguishing components that overlap in time, and it is customary to record ERPs from a variety of scalp sites for this purpose.

ERPs have become increasingly popular as a means of investigating word recognition and related processes. The most important work in this regard concerns the $\mathrm{N} 400$ component, which, as its name suggests, is a negativegoing deflection that peaks (attains its maximum amplitude) around $400 \mathrm{msec}$ poststimulus. In a variety of paradigms, the amplitude of $\mathrm{N} 400$ has been found to be inversely proportional to the extent that the item evoking it has been semantically or contextually primed by preceding items. These paradigms include the priming of target words both with a preceding sentence context (see, e.g., Kutas \& Hillyard, 1980) and with semantic associates (see, e.g., Bentin, McCarthy, \& Wood, 1985). When $\mathrm{N} 400$ is evoked by the terminal words of sentences, its amplitude is monotonically related to the words' expectancies, as indexed by cloze probability (Kutas \& Hillyard, 1984). The locus of the effects of expectancy on word identification in normal readers appears to be postlexical (Forster, 1981; Stanovich \& West, 1983). Thus, variations in the amplitude of $\mathbf{N 4 0 0}$ resulting from changes in word expectancy (and, by implication, other priming manipulations) seem more likely to reflect changes in some aspect of postlexical processing, rather than in processes mediating lexical access. One proposal is that N400 reflects the "associative activation" evoked by the conjunction of a stimulus and its context (Halgren \& Smith, 1987), a process held by these authors to be modifiable by semantic, contextual, and repetition priming. This proposal is consistent with the recent finding that contextual and repetition priming have an interactive effect on N400 amplitude (Besson, Kutas, \& Van Petten, 1989).

The effects of word frequency on ERPs in lexical decision tasks have been investigated in two studies. The principal concern of Polich and Donchin (1988) was whether the latency of the peak of the P300 component of the ERP was influenced by word frequency. The P300 (also known as P3 and as the "late positive component"; see Pritchard,
1981) is a positive-going ERP wave recorded maximally from the parietal midline, and it is a prominent feature of the ERP waveform when evoked by stimuli requiring a speeded discriminative response. P300 was of interest to Polich and Donchin (1988) because of previous work suggesting that its peak latency is correlated with the time required to categorize an evoking stimulus, yet is unaffected by factors that influence response preparation, choice, and execution (Coles, Gratton, Bashore, Eriksen, \& Donchin, 1985; Magliero, Bashore, Coles, \& Donchin, 1983). Polich and Donchin reasoned that if a word's frequency affects the speed with which it is identified, the latency of P300s to high- and low-frequency words will differ. This was the result obtained, leading these authors to argue that the locus of the word-frequency effect in lexical decision is not confined to postaccess, responserelated processing.

Smith and Halgren (1987) investigated ERPs evoked by repetitions of high- and low-frequency words. The design of this experiment was unconventional, in that, following an initial block of lexical decision trials, subsequent trials consisted of multiple repeats of the items from the first block, along with new items. Therefore the effects of a single repetition could not be determined. Smith and Halgren reported that, when presented for the first time, low-frequency words evoked more negative-going ERPs than high-frequency words did (a similar effect can be observed in the waveforms of Polich \& Donchin, 1988; see their Figure 2, p. 38). They further reported that repeated words gave rise to more positive-going waveforms than unrepeated words did, and that the frequency effect was absent in ERPs evoked by repeated items. The frequency and repetition effects were both interpreted as involving the modulation of N400. However, as is also the case with Polich and Donchin (1988), it is difficult to determine the extent that the waveforms in Smith and Halgren's (1987) study were modulated by factors other than changes in the amplitude and latency of the P300 component. As in numerous previous studies, this component was larger and peaked earlier in the conditions attracting the shortest reaction times. This may have obscured more subtle and specific ERP effects.

Partly in order to minimize the influence of the P300 component on word-evoked ERPs, Rugg and colleagues have developed a task in which no overt response to the items of interest is required. Subjects are presented with a sequence of visually presented words, some of which are repeats of preceding items. Interspersed among the words are orthographically legal nonwords, to which subjects are required to make a prompt motor response. This task ensures that although an implicit lexical decision is made to each word, the ERPs evoked by these items are uncontaminated by processes associated with overt responding. It has been found in studies based on this and similar tasks that word (and nonword) repetition is a potent modulator of ERP waveforms (Nagy \& Rugg, 1989; Rugg, 1987; Rugg, Furda, \& Lorist, 1988; Rugg \& Nagy, 1987). 
The central finding in these studies is that ERPs evoked by repeated words are more positive-going than those evoked by unrepeated words. Although largest when words are repeated immediately (i.e., with no items intervening between first and second presentations), the effect remains reliable when up to 19 items intervene between first and second presentations (Nagy \& Rugg, 1989). The ERP repetition effect seems unlikely merely to be a nonspecific response to the repetition of a stimulus. Even when words are repeated immediately, the effect is sensitive to the nature of the processing to which the words are subjected, virtually disappearing when the target/nontarget discrimination is based on physical, rather than lexical, characteristics of the stimuli (Rugg et al., 1988; Rugg \& Nagy, 1987). It seems equally unlikely that the effect is a direct reflection of the processes mediating the facilitated identification of repeated items, since its onset latency of 250-300 msec seems too late, and its duration of approximately $300 \mathrm{msec}$ too long, to coincide with the time course of lexical access (Rugg et al., 1988).

The interpretation of the ERP repetition effect favored by Rugg et al. (1988) is based on the findings that the task sensitivity of the effect results largely from changes in the ERPs evoked by unrepeated words. As noted previously, the repetition effect is greatly reduced when the target/nontarget discrimination is based on physical (e.g., letter case) rather than lexical attributes. This arises because the ERPs evoked by unrepeated words in nonlexical tasks are substantially more positive-going than in lexical ones, the differences between the ERPs evoked by repeated items contributing very little to these task-related effects. Rugg et al. accounted for these findings by proposing that words that are subjected to relatively "deep" processing (e.g., lexical analysis) evoke ERPs that contain a sustained negative-going wave. They speculated that this wave may reflect a process such as the postlexical integration of the word with the context of its presentation. Rugg et al. suggested the ERPs were more positivegoing when evoked by words subjected to "shallow" processing (e.g., determination of letter case) by virtue of the small size of this negative wave, reflecting the paucity of the stimulus-derived information that such processing makes available to subsequent processes. The greater positivity of ERPs evoked by repeated items in tasks requiring lexical analysis (i.e., the ERP repetition effect) is also held to result from the attenuation of this negative wave. In this case, the wave is attenuated, in comparison with its amplitude in ERPs evoked by an item's first presentation, either because repeated items are easier to integrate with their context, or because they are integrated less fully than when they are initially presented (cf. Jacoby, 1978).

Within the framework of Rugg et al. (1988), the ERP repetition effect is thus viewed as a sign of differences in the way that repeated as opposed to unrepeated items are encoded, rather than as a direct reflection of the retrieval of a memory about an item's prior occurrence. The explanation of the effect offered by Rugg et al. is thus very similar to that put forward by Halgren and Smith (1987) to explain the modulation of the N400 component. As will be discussed later, the ERP repetition effect seems to a large extent to be attributable to the modulation of this component.

The present experiment was done to investigate the modulation of ERPs by the repetition of high- and lowfrequency words. The experiment was based on two aims. The first was to compare ERPs evoked by unrepeated and repeated high- and low-frequency words. If the frequency effects exhibited by ERPs in response to repeated words are merely attenuated versions of the effects found with unrepeated items, no support would be forthcoming for the hypothesis that information about baseline familiarity is preserved in the face of short-term changes in local familiarity. If, however, frequency effects in ERPs evoked by repeated and unrepeated words differ qualitatively, this would provide evidence for the view that local and baseline familiarity information interact on-line, as has been proposed by two-process theories of recognition memory. ${ }^{2}$

A further aim in this study was to provide data germane to the interpretation of the ERP repetition effect, through determining whether or not the effects of word frequency and delay between successive presentations parallel those found on behavioral variables. As has already been discussed, behavioral researchers have usually reported that repetition and frequency interact, with low-frequency words exhibiting larger repetition effects. The present study allowed a similar analysis to be performed on ERP data. Also, repetition effects have been reported over delays much longer than those investigated thus far with ERPs. The present study therefore included a condition that allowed longer term ERP repetition effects to be investigated.

\section{METHOD}

\section{Subjects}

Sixteen young adults were employed, all of whom were naive as to the purpose of the experiment. Nine were female, and all but 1 male were right-handed, as determined by writing hand.

\section{Stimuli and Task}

The critical stimuli consisted of 150 high- and 150 low-frequency open class English words, drawn from Kučera and Francis (1967). The high-frequency words all had counts in the Kučera and Francis corpus of 100 or more, and the low-frequency words had counts of 1 . High- and low-frequency words were matched on a pairwise basis for initial letters and numbers of letters. One hundred nonwords were also employed. These were constructed by changing one or two letters of words to produce orthographically legal, pronounceable letter strings.

The above items were used to construct the word lists used in Phases 1 and 2 of the experiment. The Phase 1 lists consisted of 50 high- and 50 low-frequency words that were presented once only (control items), 50 high- and 50 low-frequency words that were presented twice, separated by 6 intervening words (repeated items), and 60 nonwords (targets). Four Phase 1 lists were constructed, designated 1A, 1B, 1C, and 1D. Lists $1 \mathrm{~A}$ and $1 \mathrm{~B}$ were formed from the same set of 100 high- and 100 low-frequency words, which were 
selected at random from the word pool. Along with 60 randomly selected nonwords, these words were used to form a sequence of control, repeated, and target stimuli, as described above. The only difference between Lists $1 \mathrm{~A}$ and $1 \mathrm{~B}$ was that the sequential positions in the list of the high- and low-frequency words were reversed, so as to remove any possible confound between word frequency and sequence effects. Lists IC and ID were formed similarly, but were based around a different sequence of conditions. The control items in these lists consisted of the $\mathbf{5 0}$ words from each frequency category that had not been employed in Lists $1 \mathrm{~A}$ and $1 \mathrm{~B}$.

The Phase 2 lists consisted of a random ordering of the 50 high- and 50 low-frequency words employed as control items in the corresponding Phase 1 list (old items), 50 high- and 50 lowfrequency words that had not been used in Phase 1 (new items), and 40 nonwords that also had not been seen in Phase 1 . Four Phase 2 lists were constructed: $2 \mathrm{~A}, 2 \mathrm{~B}, 2 \mathrm{C}$, and $2 \mathrm{D}$. Lists $2 \mathrm{~A}$ and $2 \mathrm{~B}$ differed only in that the sequential positions of the high- and low-frequency items were reversed between the lists; these two lists were paired with Lists $1 \mathrm{~A}$ and $1 \mathrm{~B}$. Lists $2 \mathrm{C}$ and $2 \mathrm{D}$ were paired with Lists $1 \mathrm{C}$ and $1 \mathrm{D}$, with their high-and low-frequency items similarly interchanged.

The stimuli in each list were exposed for $292 \mathrm{msec}$ within a $2^{\circ} \times 0.5^{\circ}$ window on a TV monitor. The interval between the onsets of successive stimuli was $3.7 \mathrm{sec}$. A fixation asterisk was displayed at the center of the display window other than during an interval beginning $150 \mathrm{msec}$ before until $924 \mathrm{msec}$ after the onset of each stimulus.

In both phases of the experiment, the subjects' task was to respond promptly to the nonwords, and to withhold responses to the words. The subjects were informed that they would probably notice that some of the words were more common in the English language than others were, but that this was irrelevant to the task. In the case of Phase 1 , they were also informed that some of the words would be repeats of previous items, that this was also irrelevant, and that they should concentrate on detecting and responding to nonwords as efficiently as possible. They were not informed that Phase 2 of the experiment would involve re-presentation of some of the Phase 1 items. Prior to Phase 2, they were told that some of the words would be repeats from the previous phase, and the importance of concentrating on the nonword detection task was reemphasized.

Phase 1 and Phase 2 lists were assigned to subjects so as to produce a completely counterbalanced design with respect to the serial positions of repeated high- and low-frequency Phase 1 and Phase 2 words, and the items employed as "old" and "new" in Phase 2.

\section{Procedure}

Following electrode application, the subjects were seated in front of the TV monitor. Each subject was given a thumb-activated microswitch to hold in the preferred hand, and the task was explained. The subjects were also instructed to minimize eye and body movements during the experimental runs, and to refrain from blinking during the interval in which the fixation asterisk was absent. Prior to the administration of the Phase 1 list, 24 practice trials were given with a similarly constructed list containing items not used in the experiment proper. The Phase 1 list was then presented, with rest breaks after approximately every 120 trials.

After Phase 1 was completed, the subjects rested for approximately 10-15 min, during which they drank a cup of tea and conversed with the experimenter. They were then administered the appropriate Phase 2 list, with one brief rest break after 120 trials.

\section{ERP Recording}

EEG was recorded from five scalp sites, defined by reference to the International 10-20 system (Jasper, 1958). These sites were over the frontal, central, and parietal midlines $(\mathrm{Fz}, \mathrm{Cz}$, and $\mathrm{Pz}$ ), and over the left and right temporal regions $(75 \%$ of the distance from $\mathrm{Cz}$ to $\mathrm{T} 3$ on the left, and to T4 on the right). All scalp electrodes were referred to linked electrodes placed on the mastoid processes. EOG was recorded from a bipolar electrode pair, situated on the outer canthus of the left eye and just above the right eyebrow. EEG and EOG were amplified with a bandwidth of $0.03-30 \mathrm{~Hz}$ (3-dB points), and digitized on-line at a rate of 1 point $4 \mathrm{msec}$. Sampling began $100 \mathrm{msec}$ before the onset of each stimulus, and continued for $924 \mathrm{msec}$ thereafter.

Average ERPs were formed for each subject from the words in each experimental condition of the two phases of the experiment. Only trials on which an error was not committed, and which did not contain eye-movement artifact, were used to form the averages. EOG was averaged along with the EEG to ensure that, for every subject, no stimulus-locked eye movement contaminated the ERP data.

\section{RESULTS}

\section{Phase 1}

Behavioral data. Mean reaction time with the nonwords was $839 \mathrm{msec}$, with a mean of $8.8 \%$ errors of omission. Mean false positive rate for the unrepeated highfrequency words (i.e., controls and first presentations of subsequently repeated items) was $2.4 \%$, and for repeated high-frequency words $1.3 \%$; these error rates were too low for analysis. Mean error rate with unrepeated lowfrequency items was $8.5 \%$, dropping to $4.3 \%$ in the case of repeated words. The $4.2 \%$ difference between these rates was significant $[t(15)=4.67, p<.05]$.

ERPs. Grand average waveforms from Phase 1 are shown in Figures 1 and 2 for all electrode sites. Figure 3 shows the waveforms from $\mathrm{Cz}$ in more detail, with all four experimental conditions superimposed. Waveforms for responses to unrepeated items are characterized by frontocentrally distributed $\mathrm{N} 140$ and P240 components, followed by a centroparietal negative-going component peaking at approximately $400 \mathrm{msec}(\mathrm{N} 400)$, and finally a parietal-maximum positive wave with a peak latency of approximately $530 \mathrm{msec}$ (P530). As is evident from Figure 1, the ERPs evoked by unrepeated low-frequency words are more negative-going than those evoked by highfrequency words from approximately $300 \mathrm{msec}$ onwards. As is illustrated in Figures 2 and 3, ERPs evoked by both high- and low-frequency repetitions show, in comparison with the waveforms evoked by their first presentations, a positive-going shift encompassing the $\mathrm{N} 400$. This shift is larger in ERPs evoked by low-frequency items, so that the N400 is of approximately the same amplitude in these waveforms and those evoked by repeated high-frequency words. No other effect of repetition is apparent in ERPs evoked by high-frequency words. By contrast, ERPs in response to repeated low-frequency words show a second positive shift, which is maximal in the region of P530. The shift is sufficient to make this region of the waveform more positive-going in ERPs evoked by repeated low- than in those evoked by repeated high-frequency words.

These data were quantified by measuring the mean amplitude of three latency regions of the waveforms. The regions were chosen to encompass the onset of the repetition effects (200-300 msec), to bracket the $\mathbf{N} 400$ deflec- 


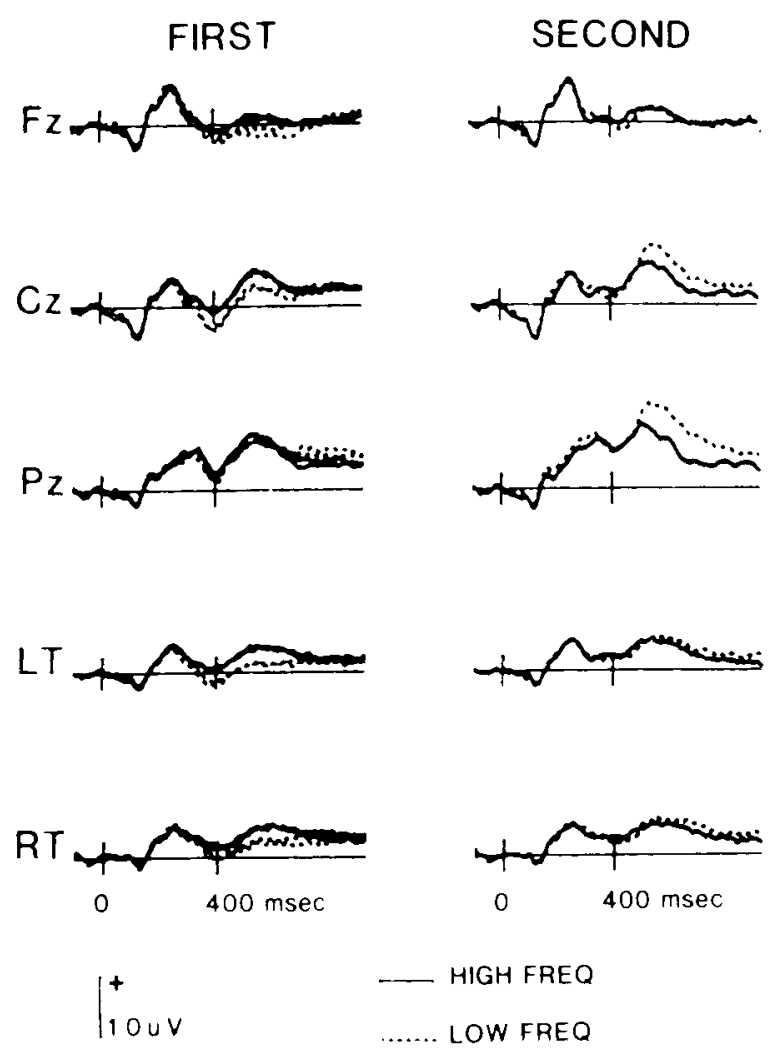

Figure 1. Grand average waveforms, from each electrode site, to first and second presentations of high-and low-frequency words in Phase 1. First $=$ control and first presentation of subsequently repeated words. Second $=$ repeated words.

tion (300-500 msec), and to encompass the apparently separate modulation of the P530 (500-800 msec). The data are shown in Table 1. Two sets of analyses were performed. First, the data from the control and the first presentations of repeated items were subjected to a repeated-measures ANOVA, with factors of frequency (high vs. low), word type (control vs. repeated), and electrode site. This allowed an assessment of both the adequacy of the assignment of items to conditions (there should be no differences between the ERPs evoked by the two word types) and the effects of word frequency. A second analysis was performed on the data from first and second presentations of repeated words. This involved the factors of frequency, repetition (first vs. second presentation), and electrode site. In the latter analyses, the reliability of repetition effects was assessed separately for ERPs evoked by high- and low-frequency words, with planned comparisons on the data collapsed over electrode sites.

In all ANOVAs, $F$ ratios are reported with degrees of freedom corrected by the Geisser-Greenhouse procedure for controlling the Type I error associated with inhomogeneity of covariance (Keselman \& Rogan, 1980).

Turning first to the 200-300 msec data, the ANOVA contrasting the ERPs evoked by high- and by lowfrequency unrepeated words gave rise to an effect of electrode site $[F(3.1,46.1)=3.83, p<.025]$, but to no effects involving frequency or word type (all $F \mathrm{~s}<1.75$ ).
An ANOVA of the ERPs evoked by first and second presentations of repeated words gave rise not only to an effect of electrode site $[F(3.2,48.1)=3.28, p<.02]$, but also to a significant repetition effect $[F(1,15)=6.06$, $p<.05]$. No other effects approached significance $(F s<1.75)$. Despite the absence of a significant inter-

\section{HIGH FREQ}

$\mathrm{Fz}$
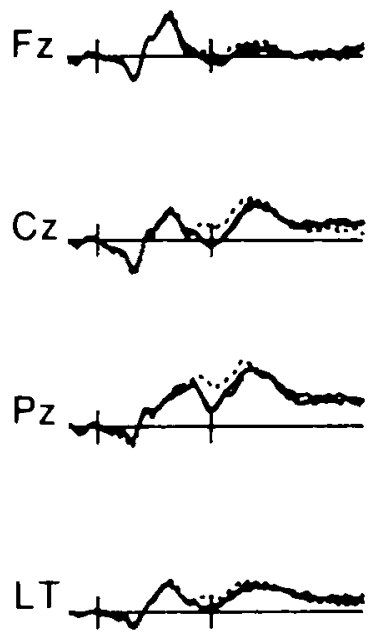

\section{LOW FREQ}
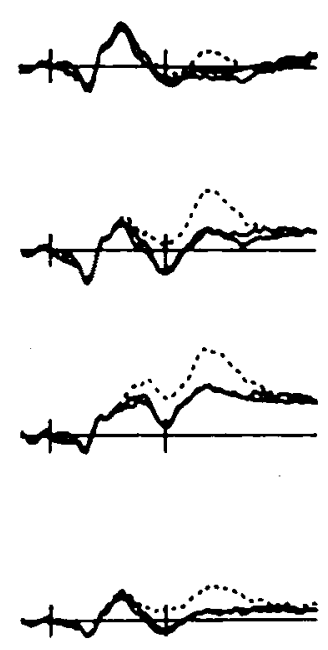

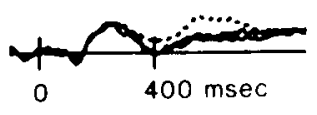

FIRST

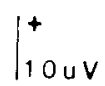

SECOND

Figure 2. Grand average waveforms from each electrode site in Phase 1, illustrating repetition effects for high- and low-frequency words. First $=$ control and first presentation of subsequently repeated words. Second $=$ repeated words.
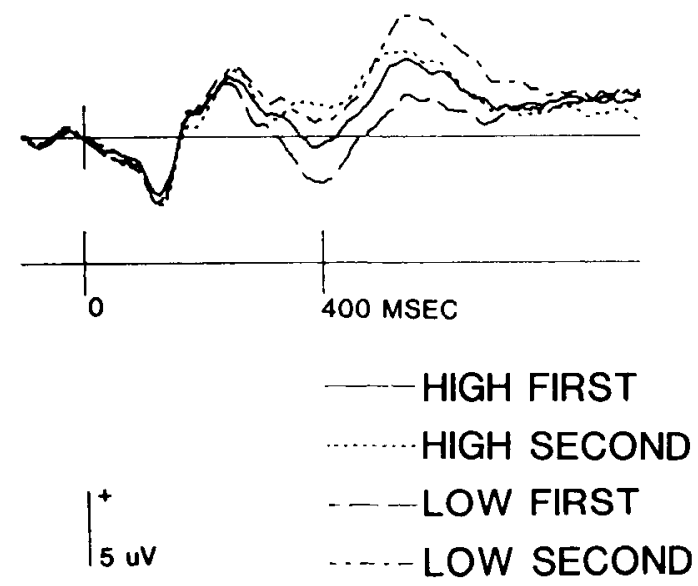

Figure 3. Grand average waveforms from the $\mathrm{Cz}$ electrode site in Phase 1, overlaying the ERPs evoked by the first and second presentations of high- and low-frequency words. 
Table 1

Mean Amplitude of the 200-300, 300-500, and 500-800 msec Latency Regions of the ERPs from Phase 1, for Each Electrode Site and Experimental Condition

\begin{tabular}{|c|c|c|c|c|c|c|c|c|c|c|}
\hline \multirow[b]{2}{*}{ Condition } & \multicolumn{5}{|c|}{ High Frequency } & \multicolumn{5}{|c|}{ Low Frequency } \\
\hline & $F_{Z}$ & $\mathrm{Cz}$ & $\mathrm{Pz}$ & $\mathrm{LT}$ & RT & $\mathrm{Fz}_{2}$ & $\mathrm{Cz}$ & $\mathrm{Pz}$ & LT & $\mathrm{R}^{\prime} \mathrm{T}$ \\
\hline \multicolumn{11}{|c|}{$200-300 \mathrm{msec}$} \\
\hline Control & 3.7 & 2.8 & 4.0 & 3.0 & 3.5 & 4.4 & 3.0 & 4.1 & 3.0 & 3.8 \\
\hline $\mathrm{RI}$ & 4.0 & 2.9 & 3.7 & 3.0 & 3.3 & 3.6 & 2.4 & 3.6 & & 3.3 \\
\hline R2 & 4. 1 & 3.0 & 4.0 & 3.3 & 3.5 & 4.2 & 3.6 & 4.9 & & 3.8 \\
\hline $\mathrm{R} 2-\mathrm{R} 1$ & 0.1 & 0.1 & 0.3 & 0.3 & 0.2 & 0.6 & 1.2 & 1.3 & 1.0 & 0.5 \\
\hline \multicolumn{11}{|c|}{$300-500 \mathrm{msec}$} \\
\hline Control & 0.0 & 0.9 & 4.5 & 1.5 & 2.3 & -0.5 & -0.5 & 3.7 & -0.1 & 1.3 \\
\hline R1 & 0.1 & 0.9 & 4.1 & 1.4 & 2.0 & -1.1 & -1.1 & 3.4 & -0.5 & 0.9 \\
\hline $\mathrm{R} 2$ & 0.6 & 2.5 & 6.2 & 2.3 & 2.7 & 0.2 & 2.3 & 6.5 & 2.0 & 2.4 \\
\hline $\mathrm{R} 2-\mathrm{R} 1$ & 0.5 & 1.6 & 2.1 & 0.9 & 0.7 & 1.3 & 3.4 & 3.1 & 2.5 & 1.5 \\
\hline \multicolumn{11}{|c|}{$500-800 \mathrm{msec}$} \\
\hline Control & 0.6 & 3.3 & 5.4 & 2.8 & 3.7 & -0.1 & 2.6 & 5.7 & 1.6 & 2.5 \\
\hline Rl & 0.7 & 3.1 & 4.9 & 2.7 & 3.4 & -1.1 & 1.8 & 5.4 & 1.3 & 1.9 \\
\hline $\mathrm{R} 2$ & 0.8 & 3.3 & 5.1 & 2.8 & 3.3 & 0.7 & 5.1 & 8.5 & 3.4 & 3.9 \\
\hline $\mathrm{R} 2-\mathrm{R} 1$ & 0.1 & 0.2 & 0.2 & 0.1 & -0.1 & 1.8 & 3.3 & 3.1 & 2.1 & 2.0 \\
\hline
\end{tabular}

Note $-\mathrm{Fz}, \mathrm{Cz}$, and $\mathrm{Pz}=$ frontal, central, and parietal midlines; $\mathrm{LT}$ and $\mathrm{RT}=$ left temporal and right temporal electrodes. R1 = first presentation of repeated items, and R2 $=$ second presentation.

action between frequency and repetition, planned comparisons revealed that although the repetition effect was reliable for the low-frequency condition [mean magnitude collapsed over electrode sites $=0.9 \mu \mathrm{V} ; F(1,15)=5.97$, $p<.05$ ], this was not so in the case of the ERPs evoked by the high-frequency words (mean magnitude $=0.2 \mu \mathrm{V}$; $F<1$ ).

The ANOVA on the $300-500 \mathrm{msec}$ latency region of the ERPs evoked by the unrepeated words gave rise to significant effects of frequency $[F(1,15)=17.09, p=.001]$ and electrode site $[F(2.2,32.8)=12.08, p<.001]$. No other effect approached significance $\left(F_{\mathrm{s}}<1.75\right)$. The frequency effect reflected the more negative-going values for ERPs evoked by low- as opposed to high-frequency words. An ANOVA of the ERPs evoked by first and second presentations of repeated words revealed main effects of frequency $[F(1,15)=5.53, p<.05]$, repetition $[F(1,15)=41.80, p<.001]$, and electrode site $[F(2.0,30.3)=14.14, p<.001]$. In addition, significant interactions were found between frequency and repetition $[F(1,15)=5.54, p<.05]$, and repetition and site $[F(2.3,35.2)=9.10, p<.001]$. The three-way interaction did not approach significance $[F(2.4,36.1)=1.15]$. The interaction between repetition and electrode site reflected the fact that for both classes of word, repetition effects were largest centroparietally. The interaction between repetition and frequency resulted from the larger repetition effects for low-than for high-frequency words (mean magnitudes, collapsed over electrodes, of $2.3 \mu \mathrm{V}$ and $1.2 \mu \mathrm{V}$, respectively). Planned comparisons revealed that both of these effects were significantly different from zero [low frequency: $F(1,15)=27.76, p<.001$; high frequency: $F(1,15)=7.06, p<.025]$.
In the case of the 500-800 msec latency region, the ANOVA of the ERPs evoked by the unrepeated words gave rise to a significant effect of electrode site $[F(2.3,34.9)=$ $19.51, p<.001]$, and to a significant interaction between electrode site and frequency $[F(1.9,28.8)=4.11, p<$ $.05]$. Other than the main effect of frequency, which was marginally significant $[F(1,15)=3.54, p<.1]$, no other effects approached significance $(F \mathrm{~s}<1.8)$. The site $\times$ frequency interaction reflected the fact that while this region of the ERPs from $\mathrm{Fz}, \mathrm{Cz}$, and the temporal electrodes was more negative-going for low- than for highfrequency words, this effect reversed slightly at Pz. An ANOVA of the first and second presentations of repeated items revealed significant main effects for repetition $[F(1,15)=25.77, p<.001]$ and electrode $[F(2.3,34.2)=$ $23.69, p<.001]$, as well as significant interactions between repetition and frequency $[F(1,15)=16.02, p=$ $.001]$ and electrode and frequency $[F(2.1,31.5)=14.54$, $p<.001]$. The three-way interaction approached significance $[F(3.1,46.2)=2.52, p<.07]$. The interaction between frequency and site reflected the trend for all electrode sites other than $\mathrm{Pz}$ to be more negative when evoked by low-frequency words. As is evident from Table 1, the interaction between frequency and repetition was caused by repetition effects' being large in the case of lowfrequency words, but essentially nonexistent in the ERPs evoked by high-frequency words. Planned comparisons on repetition effects collapsed over electrodes showed that the effects were reliable for the low-frequency $[2.5 \mu \mathrm{V}$, $F(1,15)=36.12, p<.001]$ but not the high-frequency items $(0.1 \mu \mathrm{V}, F<1)$.

The foregoing analyses concur with the impression given in Figures 2 and 3 that the repetition effects on the 
ERPs evoked by low-frequency words have an earlier onset than those evoked by high-frequency words, and that they are bi- rather than monophasic. Figure 4 shows the grand averages of the difference waveforms obtained by subtracting the ERPs evoked by repetitions from those evoked by first presentations. The more extensive, bimodal nature of the effects of repetition on ERPs with low-frequency words is clearly evident. The onset and offset latencies of these difference waveforms were determined by computing, over subjects, the $t$ value for each sampling point of the waveforms against the null hypothesis of no deviation from zero. Onset latency was defined as the time at which the $t$ value achieved significance at the $5 \%$ level, and offset latency as the time at which $t$ fell below the $5 \%$ level. The repetition effects associated with the high-frequency words were most extensive at $\mathrm{Cz}$, having an onset latency of $352 \mathrm{msec}$ and offsetting at $508 \mathrm{msec}$. At the same electrode site, the onset and offset of the low-frequency repetition effects were 252 and $740 \mathrm{msec}$, respectively.

\section{Phase 2}

Behavioral data. Mean reaction time with the nonwords was $848 \mathrm{msec}$, with a mean of $8.8 \%$ errors. Mean error rate for new high-frequency words was $0.4 \%$, and for old items $0.3 \%$. Errors for new and old low-frequency

$\mathrm{Fz}$

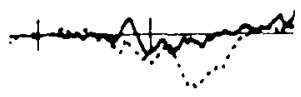

$\mathrm{Cz}$

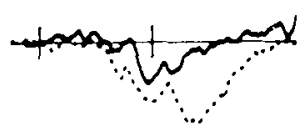

$P z$

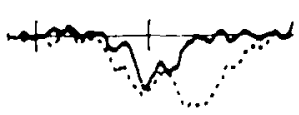

$L T$

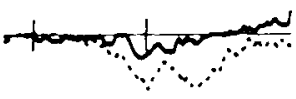

RT
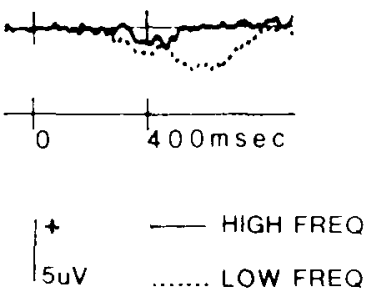

Figure 4. Grand average subtraction waveforms from each electrode site in Phase 1, formed by subtracting ERPs evoked by second presentations from those evoked by first presentations.
HIGH FREQ
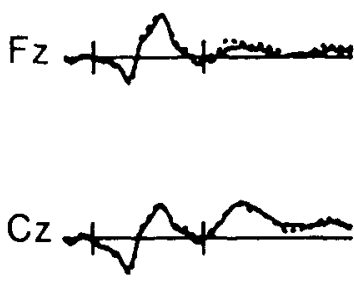

$\mathrm{LT}$

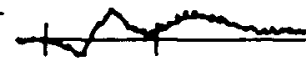

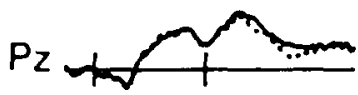

LOW FREQ
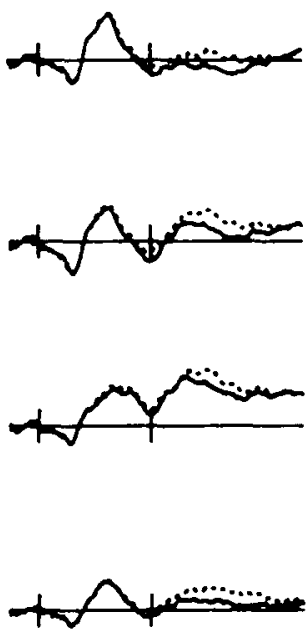

RT
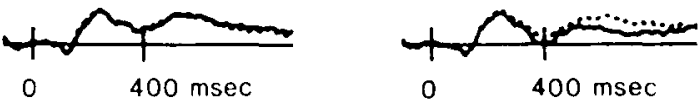

$\int_{10 u v}^{+}$

NEW

OLD

Figure 5. Grand average waveforms from each electrode site in Phase 2, illustrating the effects of repetition on the ERPs evoked by high- and low-frequency words.
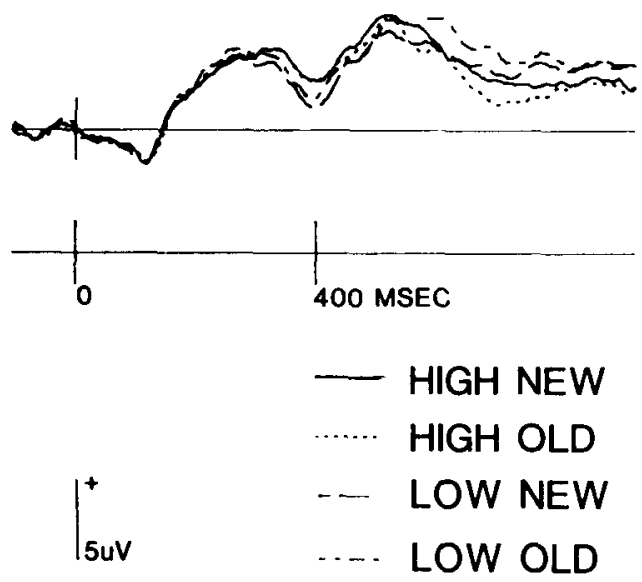

Figure 6. Grand average waveforms from the Pz electrode site in Phase 2, overlaying the ERPs evoked by new and old high- and low-frequency words.

words averaged $6.8 \%$ and $4.8 \%$, respectively; the $2 \%$ difference in these error rates was not significant.

ERPs. The grand average waveforms from Phase 2 are shown in Figures 5 and 6 , where it can be seen that they closely resemble the Phase 1 waveforms in morphology. As in Phase 1, the ERPs evoked by unrepeated (i.e., new) low-frequency words are more negative-going than those 
with unrepeated high-frequency words. Unlike in Phase 1, this effect is also apparent in the region surrounding N400 in the ERPs evoked by the old words (i.e., words repeated from Phase 1). The effects of repetition are much less marked than they are in Phase 1. They are absent in the ERPs evoked by high-frequency words, and they take the form of a relatively small positive-going shift, with an onset of approximately $500 \mathrm{msec}$, in the ERPs evoked by low-frequency items. Modulation of the $\mathrm{N} 400$ deflection by repetition is not evident in the ERPs evoked by either class of word.

The Phase 2 ERPs were quantified by measuring the mean amplitude of the three latency regions that were employed with the Phase 1 data; that is, $200-300 \mathrm{msec}$, 300-500 msec, and 500-800 msec. These data, which are shown in Table 2, were subjected to a repeated-measures ANOVA, with factors of frequency, repetition, and electrode site.

The ANOVA of the $200-300 \mathrm{msec}$ latency region gave rise to a significant main effect of electrode site $[F(3.2,47.9)=2.98, p<.05]$. No other effects approached significance $(F \mathrm{~s}<1.4)$, and planned comparisons of the high- and low-frequency repetition effects were nonsignificant in both cases $(F \mathrm{~s}<1)$. In the case of the 300-500 msec region, an ANOVA again gave rise to a reliable main effect of site $[F(1.9,28.8)=9.97$, $p=.001$ ], but unlike in the earlier region, the effect of frequency was also significant $[F(1,15)=9.42, p<.01]$. The latter effect reflected the more negative-going values for ERPs evoked by low- than for those evoked by highfrequency words. No other effect approached significance [for repetition, $F(1,15)=2.09, p>.15$; all other $F s<1$ ]. Planned comparisons on the repetition effects evoked by high- and low-frequency words were nonsignificant $(F \mathrm{~s}<1.6)$.

The ANOVA of the $500-800 \mathrm{msec}$ data yielded a significant effect of electrode site $[F(2.1,31.3)=16.73, p<$ $.001]$, as well as a marginal effect of repetition $[F(1,15)=$
$3.73, p<.1]$. In addition, significant interactions were found between frequency and site $[F(1.9,29.0)=6.37$, $p<.01]$, and repetition and frequency $[F(1,15)=6.50$, $p<.025]$. The interaction between frequency and site reflected, as in Phase 1, the tendency for low-frequency items to evoke the more negative-going waveforms at all sites other than Pz. Planned comparisons showed that, collapsed over sites, repetition effects were reliable in the case of ERPs evoked by low-frequency words $[1.4 \mu \mathrm{V}$; $F(1,15)=7.24, p<.025]$, but not for those evoked by high-frequency words $(-0.2 \mu \mathrm{V} ; F<1)$.

\section{DISCUSSION}

This experiment demonstrates that word frequency and repetition modulate ERPs in an interactive fashion. The nature of this interaction changes over the time course of the ERP waveforms, and it also varies as a function of the delay between the first and second presentations of repeated items. These findings are discussed below from two perspectives: first, with respect to the likely cognitive mechanisms underlying frequency and repetition effects, and second, with respect to light shed on the ERP repetition effect.

In both phases of the experiment, the ERPs evoked by unrepeated words were more negative-going than those evoked by high-frequency items, confirming the findings of Halgren and Smith (1987) and Polich and Donchin (1988). This difference arose in large part from the modulation of the N400 component, which was especially prominent in the ERPs evoked by unrepeated lowfrequency items. As discussed previously, a plausible interpretation of $\mathrm{N} 400$ is that it reflects a postlexical process that is invoked in proportion to the degree that the evoking stimulus and its context form an unfamiliar or unexpected conjunction. Within this framework, the present results suggest that high-frequency words form a less unfamiliar conjunction with the experimental context than

Table 2

Mean Amplitude of the 200-300, 300-500, and 500-800 msec Latency Regions of the ERPs from Phase 2, for Each Electrode Site and Experimental Condition

\begin{tabular}{|c|c|c|c|c|c|c|c|c|c|c|}
\hline \multirow[b]{2}{*}{ Condition } & \multicolumn{5}{|c|}{ High Frequency } & \multicolumn{5}{|c|}{ Low Frequency } \\
\hline & $\mathrm{Fz}$ & $\mathrm{Cz}$ & $\mathrm{Pz}$ & LT & RT & $\mathrm{Fz}$ & $\mathrm{Cz}$ & $\mathrm{Pz}$ & LT & RT \\
\hline \multicolumn{11}{|c|}{$200-300 \mathrm{msec}$} \\
\hline New & 4.1 & 3.2 & 4.1 & 3.0 & 3.8 & 4.6 & 3.4 & 4.1 & 3.2 & 3.5 \\
\hline Old & 4.6 & 3.5 & 4.4 & 3.2 & 3.8 & 4.9 & 3.9 & 4.6 & 3.3 & 3.9 \\
\hline Old-New & 0.5 & 0.3 & 0.3 & 0.2 & 0.0 & 0.3 & 0.5 & 0.5 & 0.1 & 0.4 \\
\hline \multicolumn{11}{|c|}{$300-500 \mathrm{msec}$} \\
\hline New & 0.2 & 1.1 & 4.8 & 1.6 & 2.6 & -0.5 & -0.5 & 3.6 & 0.3 & 1.3 \\
\hline Old & 0.9 & 1.5 & 4.7 & 2.0 & 2.5 & 0.2 & 0.3 & 4.1 & 0.9 & 2.0 \\
\hline Old-New & 0.7 & 0.4 & -0.1 & 0.4 & -0.1 & 0.7 & 0.8 & 0.5 & 0.6 & 0.7 \\
\hline \multicolumn{11}{|c|}{$500-800 \mathrm{msec}$} \\
\hline New & 0.8 & 2.9 & 4.7 & 2.3 & 3.2 & -1.0 & 1.5 & 4.8 & 1.1 & 1.8 \\
\hline Old & 1.1 & 2.6 & 3.9 & 2.5 & 3.0 & 0.6 & 3.0 & 5.9 & 2.6 & 3.1 \\
\hline Old-New & 0.3 & -0.3 & -0.8 & 0.2 & -0.2 & 1.6 & 1.5 & 1.1 & 1.5 & 1.3 \\
\hline
\end{tabular}

Note $-\mathrm{Fz}, \mathrm{Cz}$, and $\mathrm{Pz}=$ frontal, central, and parietal midlines; LT and RT = left temporal and right temporal electrodes. 
low-frequency words do, presumably because of their more frequent past exposures in a wider range of contexts.

To the extent that the interpretation of $\mathrm{N} 400$ as a sign of postlexical processing is valid, the ERPs evoked by unrepeated words strongly suggest that the locus in the information processing system of word-frequency effects is not confined to lexical access (cf. Balota \& Chumbley, 1984). Whether the putatively postlexical frequency effects reflected by ERPs contribute to the way frequency influences performance on word-identification or recognition memory tasks remains to be determined. It is worth noting in this respect that the interpretation of ERP frequency effects given here implies that, when presented in isolation, low-frequency words receive more extensive processing than high-frequency ones do. This is consistent with the view that the recognition memory advantage for low-frequency words is attributable, at least in part, to the more extensive processing that these words receive at the time of their encoding (see, e.g., Rao \& Proctor, 1984).

The ERP repetition effects observed pre- and post$500 \mathrm{msec}$ dissociate with respect both to the pattern of their interactions with frequency and to their relative durabilities. Turning first to the early (i.e., pre-500 msec) effect, this was evident in Phase 1 in the ERPs evoked by words of both frequency classes. As with the frequency effects discussed above, this early repetition effect appears to involve the modulation of the $\mathrm{N} 400$ component. Although the effect was present for both high- and lowfrequency words, it was of greater magnitude in the case of the latter items, so that the N400s evoked by repeated words in the two frequency classes were essentially equivalent in amplitude.

As discussed previously, it is assumed that $\mathrm{N} 400$ reflects some aspects of postlexical processing akin to the integration of a stimulus with its context. The interactive effects on $\mathrm{N} 400$ of repetition and frequency thus provide strong evidence that both these variables act to influence this aspect of postlexical processing, in addition to any effect each might also exert on lexical access. It has previously been suggested that the ease with which a word can be integrated with its semantic and syntactic context influences the efficiency with which lexical decisions can be made (see, e.g., Forster, 1981; Seidenberg, Waters, Sanders, \& Langer, 1984). If it is assumed that the same also holds true for other forms of context, possibly a mechanism exists whereby frequency and repetition could interact postlexically to affect performance on some word-identification tasks, as Forster and Davis (1984) have proposed.

It has been assumed above that frequency and repetition effects in the $\mathrm{N} 400$ latency range result from the modulation of a single ERP component. However, the data provide a hint that the effects of frequency and repetition are not entirely equivalent, in that the scalp distributions of the two effects differ, especially in the 300-500 msec latency range. Although the effects of frequency are distributed evenly over the scalp, repetition effects are maximal over the centroparietal midline. It is therefore possible that in addition to modulating a common ERP component, frequency and repetition influence the activity of other ERP generators that are more specifically associated with the one or the other variable. Thus, although these two sources of information about "familiarity" may be pooled by some of the processes active in the first $500 \mathrm{msec}$ or so following the presentation of a word, other processes also active in this time frame continue to discriminate between them.

The major theoretical focus in the present experiment was the question of whether the on-line processing of a word is influenced by its baseline as well as its local familiarity. Up to a latency of approximately $500 \mathrm{msec}$, the ERPs appear sensitive only to the latter variable, as is indicated by the finding that the effect of repetition in Phase 1 was simply to abolish the frequency effects evident in the ERPs evoked by unrepeated items. By contrast, the nature of the interaction between frequency and repetition on the P530 component provides strong evidence that processes sensitive to a discrepancy between local and baseline familiarity are active by this time. In both phases of the experiment, ERPs evoked by lowfrequency words exhibited a reliable repetition effect, whereas those evoked by high-frequency words did not. This effect seems unlikely merely to be a carry-over of the larger repetition effects exhibited by low-frequency words in earlier regions of the waveform. As can be seen from Table 2, for low-frequency words the size of the late (500-800 msec) repetition effect is roughly comparable to that of the preceding one (e.g., $3.1 \mu \mathrm{V}$ at $\mathrm{Pz}$ in both phases). If the late effect was simply a continuation of the earlier one, a similar relationship between the relative magnitudes of these two effects should also be apparent in the case of the high-frequency items. This is clearly not so, the reliable early repetition effect evoked by these items $(2.1 \mu \mathrm{V}$ at $\mathrm{Pz})$ being associated with essentially no late effect at all $(0.2 \mu \mathrm{V}$ at $\mathrm{Pz})$.

Because the late ERP repetition effect was entirely $a b$ sent from ERPs evoked by high-frequency words, it cannot merely be a consequence of boosting the local familiarity of any word, irrespective of its frequency. And the absence of a trend for greater positivity in ERPs evoked by unrepeated low-frequency words suggests that the presence of this effect for repeated items cannot be ascribed to frequency per se. A sizable discrepancy between local and baseline familiarity therefore appears to be a necessary condition for the enhancement of P530. These data are thus consistent with one of the central assumptions of two-process theories of recognition memory (see, e.g., Jacoby, 1983; Mandler, 1980), namely that a word's baseline familiarity can rapidly be retrieved and compared with its local familiarity.

The present data make two major contributions to the further understanding of the ERP repetition effect. First, it is clear that the effect can involve the modulation of at least two ERP components. One of these components occurs relatively early in the waveform, is sensitive to 
the repetition of both high- and low-frequency words, and is relatively short-lasting. The second component occurs later in time, is responsive to the repetition only of lowfrequency items (at least in the present experiment), and appears to be more durable. For reasons outlined previously, the early component is considered primarily to involve the modulation of the $\mathrm{N} 400$ component. The morphology and scalp distribution of the late component suggest that it may be an example of the P300 (Pritchard, 1981). Despite intensive empirical work over the past 20 or so years, the functional significance of this component remains unknown. However, one influential hypothesis about $\mathrm{P} 300$ proposes that it is evoked when there is a need to update working memory, as a result of a mismatch between some property of a stimulus and currently active memory representations (Karis, Fabiani, \& Donchin, 1984). The post-500-msec ERP repetition effect might therefore be conceptualized as reflecting the mismatch between the baseline familiarity of a low-frequency word, retrieved from long-term memory, and its local familiarity, derived from cues such as perceptual fluency.

There are two reasons why the late ERP effect may be independent of the processes reflected by the earlier one. First, although in Phase 1 both classes of word evoked an early effect, only the low-frequency words gave rise also to the late effect. Second, the late effect was observed for low-frequency words in Phase 2, even though the earlier one appeared to be totally absent. However, both of these dissociations are only partial. As well as giving rise to no reliable late repetition effect in Phase 1, highfrequency words yielded smaller early effects than lowfrequency words did. And the absence of an early effect for low-frequency words in Phase 2 was accompanied by a substantial decline in the size of the late effect for these items. Thus the possibility of some kind of contingent relationship between the two effects cannot be ruled out, and further evidence will be required before a firm conclusion can be drawn. This uncertainty does not compromise the conclusion drawn previously on the basis of the specificity of the late ERP repetition effect that occurs in response to low-frequency words-namely, that this specificity results from a large discrepancy between local and baseline familiarity, a discrepancy created by intraexperimental repetition. This conclusion arises directly from the nature of the repetition $\times$ frequency interaction observed in the post-500-msec latency region, and it is not predicated on any assumption concerning the nature of other processes that may be necessary for the interaction to occur.

The second contribution of the present data to the elucidation of the ERP repetition effect stems from the finding that a delay of some 15-20 min between first and second presentations eliminated the effect of repetition on the N400 component. The very similar levels of performance in the two phases of the experiment make it unlikely that this absence of a repetition effect across the phases merely reflected such factors as fatigue or practice effects. The relatively rapid decline over time of the early ERP repetition effect stands in marked contrast to the durabil- ity of repetition effects on performance in tasks such as lexical decision. These persist over intervals substantially longer than the one separating the two phases of the present experiment (see, e.g., Scarborough et al., 1977). It therefore follows that the early ERP repetition effect is very unlikely to reflect the only processes that underlie the beneficial effects of repetition on task performance.

The absence of the early repetition effect in Phase 2 is unlikely to result from a failure of explicit memory for the words presented in Phase 1. Rugg and Doyle (1990) studied recognition memory approximately $20 \mathrm{~min}$ after words were exposed in a lexical decision task very similar to the one employed in the present experiment. Discrimination between old and new words was well above chance (mean $d^{\prime}=1.28$ ), and there is no reason to believe that access to explicit memories for previously presented words would have been substantially different in Phase 2 of the present experiment. Moreover, old and new words that are successfully discriminated in a recognition memory task do not necessarily evoke different-sized N400 components (Rugg \& Nagy, 1989), indicating that the absence of old/new N400 effects cannot be taken as a sign of poor memory for previously presented words. The absence of early repetition effects in Phase 2 may reflect the fact that the context provided by this phase of the experiment was sufficiently different from that of Phase 1 to reinstate the need for the contextual integration of the words presented in the earlier phase. It seems likely that the testing of this explanation will require a more precise characterization of all the variables that create an experimental context than is presently available.

Whether or not the above explanation of the time course of the early repetition effect turns out to be valid, the effect appears to be midway in durability between the short- and long-term effects identified in previous behavioral studies (Bentin \& Moscovitch, 1988; Monsell, 1985; Ratcliff, Hockley, \& McKoon, 1985). Thus it is possible that a third form of repetition priming, with a time course similar to that of the early ERP repetition effect, awaits discovery.

In conclusion, this experiment suggests that word frequency and intraexperimental repetition have an interactive effect at multiple loci within the word-recognition system. The findings further suggest that information about a word's frequency of occurrence in the language is accessible independently of its intraexperimental familiarity, and that the discrepancy between these two variables is computed with sufficient rapidity to influence online processing.

\section{REFERENCES}

Balota, D. A., Chumbley, J. I. (1984). Are lexical decisions a good measure of lexical access? The role of word frequency in the neglected decision stage. Journal of Experimental Psychology: Human Perception \& Performance, 10, 340-357.

Bentin, S., MCCArthy, G., Wood, C. C. (1985). Event-related potentials, lexical decision and semantic priming. Electroencephalography \& Clinical Neurophysiology, 60, 343-355.

Bentin, S., \& Moscovitch, M. (1988). The time course of repetition effects for words and unfamiliar faces. Journal of Experimental Psychology: General, 117, 148-160. 
Besson, M., Kutas, M., \& Van Petten, C. (1989, May). Semantic priming and word repetition effects in sentence context: An eventrelated potentials study. Poster presented at the Ninth International Conference on Event-Related Potentials of the Brain, Noordwijk, The Netherlands.

Coles, M. G. H., Gratton, G., Bashore, T. R., Eriksen, C. W., \& DoNCHIN, E. (1985). A psychophysiological investigation of the continuous flow model of human information processing. Journal of Experimental Psychology: Human Perception \& Performance, 11, 529-553.

DucheK, J. M., NeELY, J. H. (1989). A dissociative word-frequency $\times$ levels-of-processing interaction in episodic recognition and lexical decision tasks. Memory \& Cognition, 17, 148-162.

Feustel, T. C., Shiffrin, R. M., \& Salasoo, A. (1983). Episodic and lexical contributions to the repetition effect in word identification. Joumal of Experimental Psychology: General, 112, 309-346.

FORSTER, K. I. (1976). Accessing the mental lexicon. In R. J. Wales \& E. Walker (Eds.), New approaches to language mechanisms (pp. 257-287). Amsterdam: North-Holland.

FoRSTER, K. I. (1981). Priming and the effects of sentence and lexical contexts on naming time: Evidence for autonomous lexical processing. Quarterly Journal of Experimental Psychology, 33A, 465-495.

Forster, K. I., \& DAVIS, C. (1984). Repetition priming and frequency attenuation in lexical access. Journal of Experimental Psychology: Learning, Memory, \& Cognition, 10, 680-698.

GeRNSBACHER, M. A. (1984). Resolving 20 years of inconsistent interactions between lexical familiarity and orthography, concreteness and polysemy. Joumal of Experimental Psychology: General, 113, 256-281.

GLANZER, M., \& BowLES, N. (1976). Analysis of the word frequency effect in recognition memory. Joumal of Experimental Psychology: Human Learning \& Memory, 2, 21-31.

Gordon, B. (1983). Lexical access and lexical decision: Mechanisms of frequency sensitivity. Journal of Verbal Learning \& Verbal Behavior, 22, 24-44.

GoRDON, B. (1985). Subjective frequency and the lexical decision latency function: Implications for mechanisms of lexical access. Journal of Memory \& Language, 24, 631-645.

GoRMAN, A. M. (1961). Recognition memory for nouns as a function of abstractness and frequency. Journal of Experimental Psychology, 61, 23-29.

Halgren, E., \& SMith, M. E. (1987). Cognitive evoked potentials as modulatory processes in human memory formation and retrieval. $\mathrm{Hu}$ man Neurobiology, 6, 129-139.

Hillyard, S. A., \& KUTAS, M. (1983). Electrophysiology of cognitive processing. Annual Review of Psychology, 34, 33-61.

HintzmaN, D. L. (1988). Judgments of frequency and recognition memory in a multiple-trace memory model. Psychological Review, 95, 528-551.

Humphreys, G. W., Besner, D., \& Quinlan, P. T. (1988). Eventperception and the word recognition effect. Journal of Experimental Psychology: General, 117, 51-67.

JACOBY, L. L. (1978). On interpreting the effects of repetition: Solving a problem versus remembering a solution. Joumal of Verbal Learning \& Verbal Behavior, 17, 649-667.

JACOBY, L. L. (1983). Perceptual enhancement: Persistent effects of an experience. Journal of Experimental Psychology: Learning, Memory, \& Cognition, 9, 21-38.

JACOBY, L. L., \& DALLAS, M. (1981). On the relationship between autobiographical memory and perceptual learning. Joumal of Experimental Psychology: General, 110, 306-340.

JASPER, H. (1958). The ten twenty system of the International Federation. Electroencephalography \& Clinical Neurophysiology, 10, 371-375.

Karis, D., FAbIanI, M., \& Donchin, E. (1984). "P300" and memory: Individual differences in the von Restorff effect. Cognitive Psychology, 16, 177-216.

Keselman, H. J., Rogan, J. C. (1980). Repeated measures $F$ tests and psychophysiological research: Controlling the number of false positives. Psychophysiology, 17, 499-503.

Kinsbourne, M., \& GeORGE, J. (1974). The mechanism of the word frequency effect on recognition memory. Journal of Verbal Learning \& Verbal Behavior, 13, 63-69.

Kučera, H., \& Francis, W. N. (1967). Computational analysis of present-day American English. Providence, RI: Brown University Press.

Kutas, M., \& Hillyard, S. A. (1980), Reading senseless sentences: Brain potentials reflect semantic incongruity. Science, 207, 202-205.

KuTAS, M., \& HillyaRD, S. A. (1984). Brain potentials during reading reflect word expectancy and semantic association. Nature, 307 , 161-163.

Kutas, M., \& VAn Petten, C. (1988). ERP studies of language. In P. K. Ackles, J. R. Jennings, \& M. G. H. Coles (Eds.), Advances in psychophysiology (pp. 139-188). Greenwich, CT: JAI Press.

Magliero, A., Bashore, T., Coles, M. G. H., \& Donchin, E. (1983). On the dependence of $P 300$ latency on stimulus evaluation processes. Psychophysiology, 21, 171-186.

MANDLER, G. (1980). Recognizing: The judgment of previous occurrence. Psychological Review, 87, 252-271.

Mandler, G., Goodman, G. O., \& Wilkes-GibBs, D. L. (1982). The word-frequency paradox in recognition. Memory \& Cognition, 10, 33-42.

MCCANN, R. S., \& BeSNER, D. (1987). Reading pseudohomophones: Implications for models of pronunciation assembly and the locus of the word frequency effect in naming. Journal of Experimental Psychology: Human Perception \& Performance, 13, 13-24.

McClelland, J. L., \& Rumelhart, D. E. (1981). An interactive activation model of context effects in letter perception: Part I. An account of basic findings. Psychological Review, 88, 375-407.

McClelland, J. L., \&umelhart, D. E. (1985). Distributed memory and the representation of general and specific information. Journal of Experimental Psychology: General, 114, 159-188.

MonszLl, S. (1985). Repetition and the lexicon. In A. W. Ellis (Ed.), Progress in the psychology of language (Vol. 2, pp. 147-195). London: Erlbaum.

Monsell, S., Doyle, M. C., \& Haggard, P. N. (1989). Effects of frequency on visual word recognition tasks: Where are they? Journal of Experimental Psychology: General, 118, 43-71.

MORTON, J. (1969). The interaction of information in word recognition. Psychological Review, 76, 340-354.

NAGY, M. E., \& RuGG, M. D. (1989). Modulation of ERPs by word repetition: The effects of inter-item lag. Psychophysiology, 26, 431-436.

NoRRIS, D. (1984). The effects of frequency, repetition and stimulus quality in visual word recognition. Quarterly Journal of Experimental Psychology, 36A, 507-518.

PICTON, T. W. (1981). The use of human event-related potentials in psychology. In I. Martin \& P. H. Venables (Eds.), Techniques in psychophysiology (pp. 357-395). Chichester, England: Wiley.

Polich, J., \& Donchin, E. (1988). P300 and the word frequency effect. Electroencephalography \& Clinical Neurophysiology, 70, 33-45.

Pritchard, W. (1981). Psychophysiology of P300. Psychological Bulletin, 89, 506-540.

Rao, K. V., \& Proctor, R. W. (1984). Study-phase processing and the word frequency effect in recognition memory. Journal of Experimental Psychology: Learning, Memory, \& Cognition, 10, 386-394.

RatclifF., R., Hockley, W., \& McKooN, G. (1985). Components of activation: Repetition and priming effects in lexical decision and recognition. Journal of Experimental Psychology: General, 114, 435-450.

RUGG, M. D. (1987). Dissociation of semantic priming, word and nonword repetition by event-related potentials. Quarterly Journal of Experimental Psychology, 39A, 123-148.

RUGG, M. D., DoYLE, M. (1990). Event-related potentials and recognition memory for high and low frequency words. Manuscript in preparation.

RUGG, M. D., FURDA, J., \& LoRIST, M. (1988). The effects of task on the modulation of event-related potentials by word repetition. Psychophysiology, 25, 55-63.

RugG, M. D., KoK, A., Barrett, G., \& Fischler, I. (1986). 
ERPs associated with language and hemisphere specialisation. In W. C. McCallum, R. Zappoli, \& F. Denoth (Eds.), Cognitive psychophysiology: Studies in ERPs (pp. 273-301). Amsterdam: Elsevier.

RUGG, M. D., \& NagY, M. E. (1987). Lexical contribution to nonwordrepetition effects: Evidence from event-related potentials. Memory \& Cognition, 15, 473-481.

RUGG, M. D., NAGY, M. E. (1989). Event-related potentials and recognition memory for words. Electroencephalography \& Clinical Neurophysiology, 72, 395-406.

Scarborough, D. L., Cortese, C., \& Scarborough, H. J. (1977). Frequency and repetition effects in lexical memory. Journal of $E x$ perimental Psychology: Human Perception \& Performance, 3, 1-17.

Seidenderg, M. S., Waters, G. S., Sanders, M., \& Langer, P. (1984). Pre- and postlexical loci of contextual effects on word recognition. Memory \& Cognition, 12, 315-328.

SMITH, M. E., \& HALGREN, E. (1987). Event-related potentials during lexical decision: Effects of repetition, word frequency, pronounceability, and concreteness. In R. Johnson, J. W. Rohrbaugh, \& R. Parasuraman (Eds.), Current trends in ERP research (pp. 417. 421). Amsterdam: Elsevier.

Stanovich, K. E., \& West, R. F. (1983). On priming by a sentence context. Journal of Experimental Psychology: General, 112, 1-36.

\section{NOTES}

1. An important assumption underlying the use of averaging to reveal time-locked ERP activity is that the "signal" embedded in each sample (in this case, the various components of the ERP) is invariant across samples. This assumption can be broken in a number of ways. For example, a component may vary across samples in its onset latency ("latency-jitter"), such that the average underestimates its true amplitude while overestimating its duration. Furthermore, a component that is stable in time might nonetheless vary so widely in amplitude across samples that its average is highly unrepresentative of its amplitude on the majority of individual trials. These limitations of the averaging process can in principal be overcome by analyzing single samples of EEG rather than the average of the samples, but this can only be done when the signal-to-noise ratio of the component(s) of interest is very favorable. In most cases, as in the present experiment, this is not feasible. It must therefore be borne in mind that a change in the amplitude of an ERP component need not only be attributable to a uniform change in the strength of the activity of its intracerebral sources. This problem should not be exaggerated, however; an explanation of an ERP amplitude change entirely in terms of changes in intersample variability is not always plausible. Furthermore, the mere demonstration that an experimental variable has a reliable effect on an ERP component may of itself be informative.

2. ERP effects that differ qualitatively do so in terms of either scalp distributions or polarities. In either case, it is likely that different intracerebral generators are responsible for the effects, with the implication that different cognitive processes are involved (see also Rugg, 1987).

(Manuscript received May 8, 1989; revision accepted for publication September 28, 1989.) 